\title{
Wouter F. M. Henkelman, Matthew W. Stolper. Ethnic identity and the ethnic labelling at Persepolis : the case of the Skudrians
}

\section{Rémy Boucharlat}

\section{(2) OpenEdition}

1 Journals

\section{Édition électronique}

URL : http://journals.openedition.org/abstractairanica/40291

DOI : 10.4000/abstractairanica.40291

ISSN : 1961-960X

Éditeur :

CNRS (UMR 7528 Mondes iraniens et indiens), Éditions de l'IFRI

\section{Édition imprimée}

Date de publication : 1 décembre 2013

ISSN : 0240-8910

Référence électronique

Rémy Boucharlat, « Wouter F. M. Henkelman, Matthew W. Stolper. Ethnic identity and the ethnic labelling at Persepolis : the case of the Skudrians », Abstracta Iranica [En ligne], Volume 32-33 | 2013, document 75, mis en ligne le 01 juillet 2016, consulté le 26 septembre 2020. URL : http://

journals.openedition.org/abstractairanica/40291; DOI : https://doi.org/10.4000/abstractairanica. 40291

Ce document a été généré automatiquement le 26 septembre 2020.

Tous droits réservés 


\title{
Wouter F. M. Henkelman, Matthew W. Stolper. Ethnic identity and the ethnic labelling at Persepolis : the case of the Skudrians
}

\author{
Rémy Boucharlat
}

\section{RÉFÉRENCE}

Wouter F. M. Henkelman, Matthew W. Stolper. «Ethnic identity and the ethnic labelling at Persepolis : the case of the Skudrians ", in : P. Briant, M. Chauveau, éds., Organisation des pouvoirs et contacts culturels dans les pays de l'empire achéménide. Paris, 2009, p. 271-329. (Persika, 14)

1 Dans les tablettes inscrites de Persépolis, 26 ethnonymes sont attestés, soit presque tous les «peuples » représentés sur les bas-reliefs ou cités dans les inscriptions royales, même si les équivalences ne sont pas totales (Maciens peuvent être Arabes, Paricani, Arachosiens, etc.). Parmi ceux-ci, les occurrences de «Skudra» sont les plus nombreuses, mais sans oublier qu'à Persépolis un même groupe de travailleurs ou de voyageurs peut être attestés par plusieurs tablettes, qui, chacune, mentionne le plus souvent la délivrance de denrées (orge, farine, bière, etc.). Ces Skudra sont également bien présents dans les inscriptions royales, ainsi que dans des tablettes de Babylonie plus récentes (règnes d'Artaxerxès I et Darius II). À Persépolis, ils sont mentionnés dans 78 tablettes, et sont localisés dans différentes sous-régions au nord et à l'ouest de la résidence. Ces Skudra sont en général identifié avec les Thraces, mais, pour certains, pourraient englober des Phrygiens; ce serait donc, vu de la Perse, les populations vivant de part et d'autre du Bosphore. 


\section{AUTEURS}

RÉMY BOUCHARLAT

CNRS, Lyon 